\title{
SARS-CoV-2 aerosol and droplets: an overview
}

\author{
Udaykumar Ranga ${ }^{1}$ (D)
}

Received: 24 August 2020/Accepted: 26 January 2021/Published online: 22 April 2021

(C) Indian Virological Society 2021

\begin{abstract}
Aerosol particles can spread respiratory infections, especially those caused by viruses; however, the perceived threat is small for many technical reasons, as identified in this article. Under controlled conditions, aerosol particles can travel up to a distance of 28 feet (or $8 \mathrm{~m}$ ); however, such aerosol particles are less likely to have sufficient quantities of viable viruses to spread infection. Additionally, nearly all the experimental models examined the behavior of the aerosols only in confined spaces, not in open areas; these findings, therefore, cannot be considered generally applicable. In the absence of scientific information and education, only misconceptions, unfounded fears, and unsubstantiated myths will prevail. Given that an effective vaccine and drugs are still not available, prevention remains the only option of protection against SARS-CoV-2, the new coronavirus. Wearing a mask is not only necessary but also critical to reduce the probability of viral spread by contact (fomite), not aerosol, transmission.
\end{abstract}

Keywords Virus - Coronavirus · SARS-CoV-2 - COVID19. Aerosol particle $\cdot$ Facemask

\section{Introduction}

There has been much concern recently regarding the spread of SARS-CoV-2, the new coronavirus, by aerosol. People expressed similar concerns during previous viral and

Udaykumar Ranga

udaykumar@jncasr.ac.in

1 HIV-AIDS Laboratory, Molecular Biology and Genetics Unit, Jawaharlal Nehru Centre for Advanced Scientific Research, Jakkur (PO), Bangalore 560 064, India bacterial epidemics and pandemics. Based on the recommendation of the World Health Organization (WHO, https://www.who.int/csr/bioriskreduction/infection_con trol/publication/en/), many nations, including India, make it mandatory to maintain a distance of 3 to 6 feet ( 1 to $2 \mathrm{~m}$ approximately) to prevent viral spread between subjects. However, a recent report showed that SARS-CoV-2, the new coronavirus, remains alive for hours in dried aerosol droplets [1]. This study stirred a debate within the scientific community, although it did not experimentally prove that the new coronavirus can spread by aerosols [2]. Additionally, previous research demonstrated that aerosol particles could travel a distance much longer than 6 feet, even up to 28 feet [3]. In this backdrop, there has been much concern whether viruses can transmit through aerosol droplets. The primary aim of this article is to present to the reader the available experimental evidence regarding the airborne transmission of pathogenic organisms.

Ironically, there are alarming levels of misinformation, even within scientific communities on facts related to coronaviruses and their transmission. The new coronavirus is undoubtedly dangerous; therefore, one must know how to protect oneself. The virus, however, is not as virulent as we imagine. The virus infects many but harms a few especially those with comorbidities and other complications $[4,5]$. Compared to many other viruses, such as Ebola, Nipah, measles, HCV, and HIV, the new coronavirus is docile. The strength of the coronavirus is in its ability to spread; therefore, in the numbers it can infect. What makes the new coronavirus so infectious is a subject of research which may take a few years to unravel. 


\section{What are aerosol particles and droplets?}

Aerosols and droplets differ mainly in size-the diameter of which is measured in micrometers $(\mu \mathrm{m})$. People spew plumes of respiratory particles of many sizes, primarily from the mouth, as they perform normal activities, such as breathing, talking, singing, coughing, whistling, and sneezing. The population of respiratory particles emitted by the same person may differ considerably in size (1 to $2000 \mu \mathrm{m}$ or even larger) and number (thousands to millions) from one respiratory activity to another one [6]. However, the techniques used to measure the number and size distribution of the respiratory particles emitted by people doing different activities are diverse and have often yielded contradictory data [7]. Additionally, different people emitted respiratory particles of different properties during the experiments to the extent that a generalization becomes arbitrary [8]. The population of respiratory particles emitted by the same person differed in size and number while talking vs. coughing vs. sneezing [6]. Subjects containing respiratory infections generated relatively larger size particles as compared to healthy persons [9]. Notwithstanding the logistic difficulties and technical limitations, a few general conclusions can be drawn from the experimental data for meaningful inference.

A person, while coughing or talking, emits a dense cloud of respiratory particles (see Fig. 1). The behavior of the particle cloud is dynamic. As the particles leave the mouth, two crucial changes alter the characteristics of the particles spontaneously, within less than a second-typically, within milliseconds. All the particles lose water shrinking in size approximately to half their original size [7]. The smaller particles of a size of $10 \mu \mathrm{m}$ or less dry-up to become 'aerosol nuclei' that, being buoyant, hang in the still air of a confined space. Given the viscous nature of the aerosol particles, the opposite also happens-the particles start to fuse to generate particles of a larger size. The process of droplet coalescing is so rapid that within milliseconds progressively larger droplets form that swiftly drop under gravity and cover various surfaces in the room. Those particles which fall to the ground and surfaces can be transmitted to people when they touch these surfaces, a process known as contact or fomite transmission. Contact transmission, not aerosol transmission, represents the predominantly major route by which viruses spread because more than $99 \%$ of the respiratory particles fall to the ground or coat the surfaces within seconds to minutes $[6,9,10]$. Environmental factors such as humidity and temperature can have a profound impact on these processes, either accelerating or slowing these processes. When the humidity is high ( $80 \%$ or higher), the particles travel farther in the air, thus, enhancing the range of transmission. A higher level of humidity can also make the particles fuse with one another at a faster rate than usual. A larger particle, however, cannot travel far in air and will drop to the ground under gravitation, thus, reducing the chances of airborne spread of the viruses.

\section{Experimental models examined only confined spaces}

Importantly, the above analysis applies only to confined spaces without proper ventilation, such as classrooms and crowded corridors. The behavior of the respiratory particles is profoundly different in open areas where the wind will be a critical parameter to consider. In the presence of wind, the aerosol particles will be dispersed and diluted to infinity; hence they cannot serve as a potential source of contamination. It is not surprising that most of the experimental models and computer simulations have generated data only in confined places, and not in open spaces.

Respiratory particles may be classified into two categories depending on two essential characteristics-the depth that these particles can reach in the lung and the distance they can travel in the air. Only particles of $10-\mu \mathrm{m}$ size or smaller can reach the deeper regions of the lung and establish infections of the lower respiratory tract [11]. In contrast, particles larger than $20 \mu \mathrm{m}$ cannot reach these deeper regions of the lung as the ciliary hair of the respiratory tract filters them. Droplets above $20 \mu \mathrm{m}$, therefore, are capable of establishing only upper lung respiratory infections. Hence, for practical consideration, respiratory particles $10 \mu \mathrm{m}$ or smaller must be considered as aerosol and all other particles larger than this size as respiratory droplets. There is one more difference. Only smaller particles can travel farther, even up to 28 feet [3]. These smaller aerosols can also remain suspended in the still air for prolonged periods, minutes, or hours before they fall to the ground. Hereafter, aerosols and droplets will be referred to as the respiratory particles of a diameter of $10 \mu \mathrm{m}$ or smaller and $20 \mu \mathrm{m}$ or larger, respectively.

Of note, the distinction between aerosol particles and droplets can be blurred at times because the respiratory droplets emitted by a person represent a continuum of particles from very small to very large sizes. Additionally, depending on the wind factor, relatively small droplets in the range of $20-50 \mu \mathrm{m}$ may behave like aerosols, especially if the wind speed is high. In addition to the wind, the levels of temperature, relative humidity, and presence of mucous in the respiratory particles can significantly influence the behavior of these particles. Thus, although the size of $10 \mu \mathrm{m}$ may serve as a convenient measure to make a distinction between aerosol particles and droplets, and such 

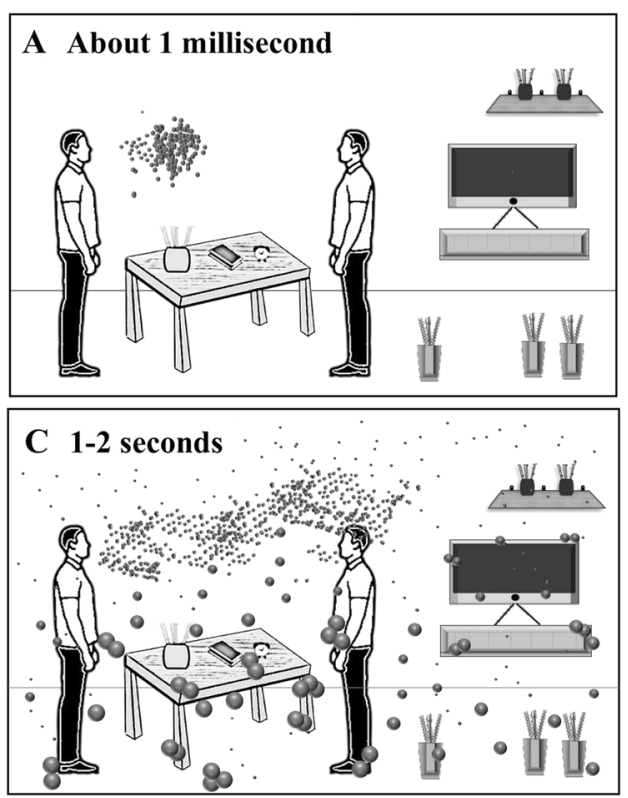

Fig. 1 The behavior of a plume of respiratory particles. a A heterogeneous population of respiratory particles is released following an expiratory activity (from the left person). b The particles undergo two critical changes in less than a second. All particles lose water and dry to approximately half of their original size in milliseconds. Those particles whose diameter is $10 \mu \mathrm{m}$ or less remain suspended in the air for minutes to hours. Many particles, especially bigger droplets, fuse to make even bigger masses of droplets that rapidly settle on surfaces under gravity, all this within a minute. c More than $99 \%$ of the particles settle on surfaces including hands, skin, clothes, floor, walls, and objects of all kinds such as the table, $\mathrm{TV}$, pencils, book, phone, and the like, and transmit infections by contact. d After the larger droplets have settled down, the aerosol particles remain hung in the air for extended periods, especially in a crowded room and in the absence of ventilation. However, only a small proportion of these particles are within the reach of breathing.

distinction mostly holds, this cutoff need not be considered as sacrosanct [11].

\section{The potential of aerosol particles transmitting infection is limited}

The emerging epidemics and pandemics, over the past century, of many respiratory infections including many viral infections, such as smallpox, chickenpox, measles, influenza, Ebola, SARS, and MERS and bacteria, such as tuberculosis and streptococci inspired a large number of scientific studies to examine the potential of respiratory particles spreading infection. While studies based on the influenza virus have been instrumental in understanding the nuances of aerosol transmission, a body of literature has emerged in recent months from the new coronavirus itself. Most of the previous studies concluded that aerosol particles are not a potential source of airborne transmission of many viral infections, although the chances are not nil.
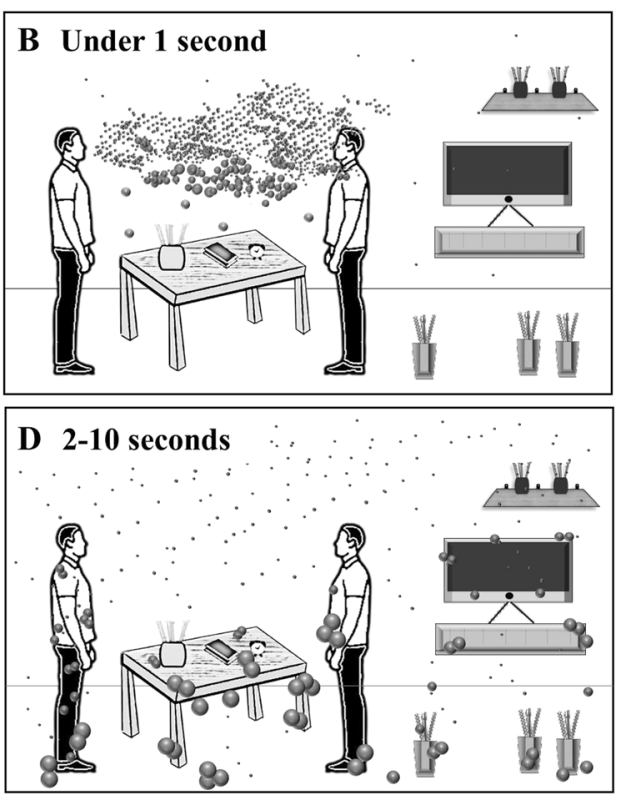

Additionally, only a small number of these particles contain pathogenic germs. At a high percentage of humidity ( $80 \%$ or more) and high temperature $\left(30{ }^{\circ} \mathrm{C}\right.$ or above), the aerosol-laden microorganisms are inactivated rapidly. Since aerosol-borne viruses represent less than $1 \%$ of the total respiratory particles released originally, the real risk of transmission is not by breathing the aerosol particles but by touching the contaminated surfaces where the droplets have fallen, which include the contaminated hands and all the inanimate surfaces in the room. In summary, big droplets are not a problem for airborne transmission of viruses since the droplets settle down. The smaller aerosol particles are also not a problem because they do not carry enough viruses. Watch the video on YouTube of the behavior of a plume of respiratory particles in less than a second emitted from a sneeze: https://www.youtube.com/watch?v=piCWFgwysu0. Note how rapidly the particles fuse and fall

Several technical reasons justify this conclusion as highlighted below,

1. Aerosol among respiratory particles represents a smaller proportion: Aerosol particles represent an exceedingly smaller proportion of the overall number of respiratory particles emitted. Several studies found that aerosol particles constitute less than $1 \%$ of the total particles emitted in a single expiration event $[6,10,12]$. In contrast, droplets of $50 \mu \mathrm{m}$ or larger size constitute more than $99 \%$ of the respiratory particles emitted. Such larger droplets quickly settle on surfaces under gravity and maintain the potential for contact (fomite) transmission.

2. Non-pathogenic commensal microorganisms out-compete pathogenic germs: The oropharyngeal region of a healthy person contains a multitude of microorganisms, including bacteria, yeast, protozoa, fungi, viruses, and other organisms that are commensal and non-pathogenic. At least 700 different strains of bacteria alone 
have been identified using next-generation sequencing technologies in the oral cavity of healthy subjects. The number of bacteria alone is expected to be a billion cells per $\mathrm{ml}$ of saliva in a healthy person [13], and a comparable number of viruses have also been identified from human saliva $[14,15]$. At any phase of the viral infection, the pathogenic viruses are outnumbered by commensal microorganisms by a vast margin; and the pathogenic viruses must compete with the commensal microorganisms for space in the aerosol particles [16, 17]. Aerosol particles are small, therefore, have limited space for cargo. An aerosol particle of $10 \mu \mathrm{m}$ can hold a fluid volume of approximately 100 picolitres, which is 10 billion times smaller than a liter. Importantly, most aerosol particles are empty and may not contain any microorganisms at all-commensal or pathogenic $[8,16]$. Of note, the relative size of many commensal bacteria is in the range of $0.5-10 \mu \mathrm{m}$ and that of commensal yeast or fungi $0.5-30 \mu \mathrm{m}$. Many bacteria and yeast exist as clusters of many cells. Thus, an aerosol particle of $10 \mu \mathrm{m}$ may typically contain one or a few such commensal bacteria and no pathogenic viruses. As a consequence, many aerosol particles may not harbor pathogenic viruses [7]. In the case of 'super spreaders', however, the number of particles emitted and the proportion of particles containing pathogenic germs can be higher as compared to other subjects [6, 18].

3. Aerosol particles can travel beyond six feet in confined spaces: The plume of small aerosol particles can remain suspended in a confined space, such as a classroom or a crowded hospital corridor, for several minutes to hours. Under the influence of air currents, these particles can spread around in the space and can travel beyond six feet. Some studies found that such particles can be detected at distances as far as 26 feet [3]. However, it is necessary to note that nearly all the studies examined the distances these particles traveled under control conditions in a laboratory setting or confined areas such as a room or a corridor but not in open spaces. Many of these studies represent only theoretical and mathematical models, not using human subjects [3]. Such studies fail to take into account the effect of aerosol dilution in an open space and the impact of the open-air factor (see below). The findings of such studies, therefore, must be interpreted with caution and should not be generalized.

4. 'The open-air factor' inactivates aerosol-laden pathogens: In open spaces, aerosol particles are not only diluted to an extreme extent that they do not present a risk anymore, but the viruses are also inactivated at a rate even faster than inside of a confined area. A multitude of several environmental factors collectively known as the 'open-air factor' inactivates the aerosolladen microorganisms at a faster rate. Many highly reactive chemical species, including ozone, ozonized cyclohexene, the UV rays, high humidity, temperature, and other factors are believed to be responsible for the observed effect [19-21].

5. Aerosols are generated at the front end of the mouth: Respiratory particles are produced mostly at the front (anterior) end of the mouth [7]. Normal commensal microorganisms abounding all the regions of the mouth and saliva are packaged into these particles preferentially. In contrast, infectious viruses such as coronaviruses are typically located deep in the lung tissues or on the nasopharyngeal surfaces, far away from the site of the generation of the respiratory particles. Therefore, except for a deep cough and sneeze, other routine activities of infected subjects do not produce a large number of respiratory particles laden with pathogenic viruses. Importantly, whether or not an event of cough can play a significant role in transmitting aerosol infection in a confined space is controversial [17, 22], by extrapolation, the risk of an expiratory activity, such as talking, spreading a viral infection is indeed minimal. Importantly, most of the experimental models, using human volunteers or experimental animals, fail to take the significance of the anatomical differences of the aerosol generation into account.

6. A single virus particle may not initiate a new infection: Just one to ten viable TB bacteria are sufficient to cause a new infection [23]; however, this is not the case with enveloped viruses. A large number of viral particles will be needed to start a new infection. The infectious doses (ID) are experimentally determined using diverse experimental strategies, including tissue culture (TCID) or plaque (PID) counting technique. Each of these units, in turn, will contain a few hundred to one thousand viral particles. For example, for influenza A virus, 1-120 TCID $_{50}$ doses of the virus was required in an experiment using human volunteers [24]. The number of viral particles present in one TCID $_{50}$ unit was estimated to be 350-600 in one study [25], and approximately one thousand in a different study [26]. There are multiple reasons why a small number of virus particles cannot initiate a new infection. A large number of viral particles are nonviable due to genetic variation or morphological defects, although the magnitude of genetic variation of the new coronavirus appears to be low [27]. The target cells of the lung and the respiratory tract are not openly accessible to the virus as these surfaces are covered by a thick mucous layer, which represents a host protective mechanism. Additionally, the host cell contains many molecular sensors to detect the presence of a 
virus, viral products, and viral nucleic acids to identify and eliminate the threat using a variety of innate defense strategies [28, 29]. Thus, establishing a productive infection is not a simple task for a virus. Although the minimal quantities of the new coronavirus needed to initiate a new infection by the aerosol route are yet not known, such estimates for the endemic coronaviruses are available, and these figures are comparable to other respiratory viral infections $[10,30]$. Of note, since the risk of infection is cumulative, directly proportional to the duration of exposure, repeated inhalation of several particles containing smaller doses of the viruses can lead to an event of infection. This fact must be taken into consideration while evaluating risks.

7. Coronavirus numbers drop to non-infectious levels within a week or two: Several studies failed to isolate infectious new coronavirus using cell culture within 10-15 days from the time of the initial infection, although the presence of the virus could be still detected in the body fluids using an RT-PCR (WHO COVID-19 Scientific Brief, 17 June 2020 available at, https://www.who.int/publications/i/item/criteria-forreleasing-covid-19-patients-from-isolation). RT-PCR is a powerful diagnostic technique that can detect as few as 20-100 viral RNA molecules in the sample. However, such a small number of virus particles may not be enough to rescue the virus using cell culture. Several studies detected the presence of the RNA of the new coronavirus in the environmental samples collected from a hospital setting where COVID-19 patients were treated $[31,32]$. The presence of viral RNA in air or surface samples does not, however, mean the existence of an infectious viral particle in these samples. The data allude to the fact that the minute quantities of the virus present in the body fluids or environmental samples may not be sufficient to pose a threat of an airborne infection below a threshold limit.

8. Enveloped viruses are less stable in aerosol particles, especially at high temperature and humidity: Given their small volume, aerosol particles are desiccated at a very rapid rate, often within milliseconds to seconds [7]. Additionally, unlike bacteria or yeast, viruses lack a protective cell wall that offers mechanical stability; therefore, they are more susceptible to temperature and drying. Microorganisms such as the tubercle bacillus and the poxviruses (smallpox and chickenpox) are quite stable in the aerosol particles and remain viable for an extended period despite evaporation. Such organisms can effectively travel longer distances by the aerosol medium [11]. Similarly, DNA viruses, such as varicella-zoster virus, the chickenpox virus, were shown to spread across rooms in a health care center through corridors [33, 34]. In contrast, enveloped RNA viruses, such as influenza and coronaviruses, may not be as stable in dried aerosol nuclei for extended periods, and this factor may limit the ability of these viruses to spread by aerosol [35]. The influence of drying on enveloped viruses, such as influenza and coronaviruses, is much more severe as compared to bacteria. The quick elimination of water from aerosol has a detrimental effect on the stability of the viruses, especially at high humidity, $80 \%$ or above [35]. The presence of water and salts is vital for maintaining the integrity of the lipid membrane and the conformation of the envelope or spike proteins on the viral surface. Shedding of the viral surface proteins or deformation of the lipid membrane can lead to permanent inactivation of the viral particles. For instance, infection of guinea pigs with an influenza viral strain was more efficient at a low temperature of $5{ }^{\circ} \mathrm{C}$ than at a higher temperature of $20^{\circ} \mathrm{C}$ [36]. Similarly, in an experiment conducted at $30^{\circ} \mathrm{C}$, the influenza virus present in aerosol, but not on surfaces, was effectively inactivated and failed to infect guinea pigs [37]. These data are suggestive that enveloped viruses are highly prone to inactivation in aerosol by temperature and high levels of humidity. Indeed, the lipid membrane of the influenza virus was experimentally shown to contain an ordered structure at a low temperature than ambient temperature, suggesting that high temperatures distort the lipid bilayer of the virus [38].

\section{Enveloped viruses are not stable on diverse surfaces for extended periods}

How stable is the new coronavirus on surfaces? Abundant information is available on the stability of enveloped viruses on general and metal surfaces; however, there is no single answer to this question. The rate of inactivity varies between even closely related viruses and depending on the nature of the surface. The porosity of the substrate surface, such as tissue paper, newspaper, cardboard, and the like, appears to inactivate the virus at an accelerated rate. In a study, live coronavirus could not be recovered from tissue paper after $30 \mathrm{~min}$ of incubation, or from a cloth or wood surface after a day. Likewise, a different study found that SARS-CoV-1 and SARS-CoV-2 viruses were inactivated on a cardboard surface in 8 and $24 \mathrm{~h}$, respectively [1]. Materials such as tissue paper and newspaper are not only porous with enlarged surface areas but they also rapidly absorb fluids, thus, subjecting viruses to harsh drying conditions leading to their inactivation. Influenza viruses 
were shown to survive on currency notes for several days [39]. The stability of coronaviruses on currency notes has also been demonstrated for up to two days. Importantly, studies of this kind use very high doses of virus, typically in the range of $10^{5}$ to $10^{7} \mathrm{TCID}_{50}$ units per assay, which is necessary to quantitate the remaining virus at the end of the experiment. In natural conditions, such high concentrations of viruses are not encountered.

Extrapolation of these results to porous and absorbent surfaces, such as walls of houses, alludes to rapid inactivation of viruses fallen on them, especially if these walls are coated with lime-containing materials rich in calcium salts. In contrast, enveloped viruses are relatively stable on non-absorbent surfaces such as tiles and plastic materials. Viable coronaviruses were recovered from plastic surfaces after $72 \mathrm{~h}$, although a large quantity of the initial inoculum was inactivated [1]. Viruses deposited on walls or floors covered by non-absorbent materials such as tiles are likely to remain infectious for longer periods than on surfaces that dehydrate the droplets. The rate of viral inactivation was rapid on the surfaces of some metals such as copper as compared to others such as steel. In summary, contact transmission of viral particles from surfaces of all kinds remains a possibility. However, the nature of the material and its surface can significantly influence the survival of enveloped viruses and their transmission [40]. Absorbent materials such as paper and porous walls inactivate viruses at a rapid rate as compared to nonporous surfaces.

Surprisingly, viruses are rapidly inactivated on the human hand. Influenza viruses transmitted to hand from a contaminated surface remained viable for only 5 to $10 \mathrm{~min}$ [35, 40]. Indeed, the short time duration is sufficient enough to permit self-inoculation. On the other hand, the short span of survival of viruses on the hand also alludes to a possible evolutionary selection [41]. Molecular biologists are aware of the presence of abundant quantities of RNAse, an enzyme that digests RNA, on the skin of human beings and animals, especially the hands [42, 43]. It would be interesting to examine if human hands also secrete protease, lipases, and other nucleases as a defense strategy against microorganisms since hands are instrumental in contact transmission of many microorganisms.

\section{Concluding remarks}

The specific knowledge on the new coronavirus has been emerging and will continue to emerge in the coming years. In many aspects, the new coronavirus behaves like the older coronaviruses and other respiratory viruses; however, there are significant differences, especially in the ability to spread among populations. Viruses and other pathogenic organisms, especially those spreading through the air, use multiple pathways towards infection. Given the limitations of available technologies to measure the size and behavior of aerosol particles and the infectivity of the viral particles in the respiratory particles, such knowledge is slow in emerging, and the data generated are likely to be controversial. The small size of the viral particles, and their inability to proliferate independently, only make these technical difficulties more challenging. The relative merit of tiny aerosol particles vs. droplets (airborne vs. fomite transmissions, respectively) in transmitting respiratory viruses is difficult to determine. The potential of small aerosol particles spreading coronaviruses cannot be ruled out; however, the probabilities are indeed low.

The episode of the Amoy Gardens housing estate in Hong Kong might be considered an aberration. SARS$\mathrm{CoV}-1$ virus from a single index case is believed to have infected nearly 300 people residing in more than 150 apartments of a 15-block residential complex. Although overwhelming epidemiological evidence points at the possibility of an airborne transmission [7], alternative possibilities have also been proposed [44]. Importantly, there is no assertive experimental data available to confirm airborne transmission beyond doubt in this case.

Vaccines cannot be a solution to eradicate an acute infection such as SARS-CoV-2, given the transient nature

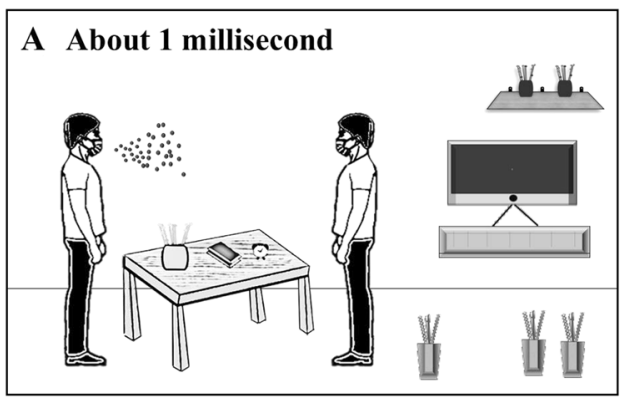

Fig. 2 When people wear masks, in a confined space, the dissemination of the respiratory particles is curtailed to a significant extent. The reduced generation of respiratory particles will result in lessened

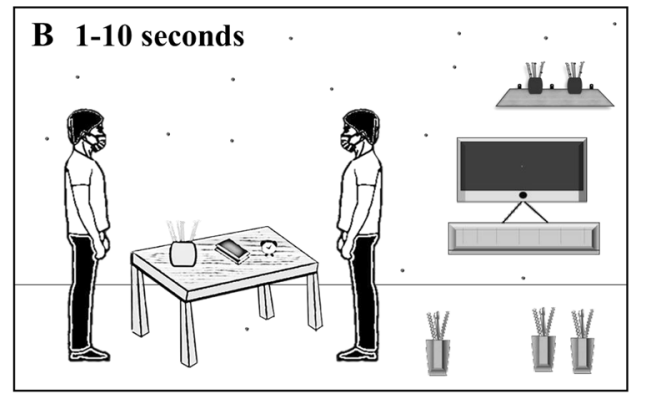

surface contamination, and diminished chances of contact infection of diseases. (Cartoon: Chhavi Saini) 
of the infection. Logistic difficulties and the enormous costs associated with the production and distribution of vaccines can wreak havoc on the economies of many nations. Anti-viral drugs have great potential to control viral dissemination; however, these medicines are yet to emerge. The anxiety regarding the new coronavirus among non-technical populations is justified and understandable. The root cause of the anxiety lies more in the lack of scientific education and, importantly, the absence of supportive administrative structure. India spends a meagerly amount on primary healthcare as compared to several developed countries and the least among even the BRIC nations. India devotes only $3.6 \%$ of its GDP, on healthcare, including out-of-pocket public spending (Puja Mehra, Live Mint, 08 Apr 2020), as compared to the developed nations the US (16.9\%), Germany (11.2\%), France (11.2\%), Japan $(10.9 \%)$, and even the mean expenditure of the OECD countries (8.8\%). Brazil spends the most $(9.2 \%)$, followed by South Africa (8.1\%), Russia (5.3\%), China (5\%). Although India contains the largest primary health care network in the world, the health care centers are generally understaffed and lack medicines.

Given the lack of necessary medical infrastructure, India is not in a position to face the challenges of the most severe medical calamity the century has been witnessing. People have seen the inhuman ways of handling migrant worker issues. They note the way people have been dying on the doorsteps of the clinics unable to find a bed in these hospitals. The unhygienic conditions of the government hospitals represent a more worrisome experience than the threat the virus itself poses. The hefty bills of the corporate hospitals that run into lakhs of Rupees loom large on the psyche of the people. Thus, people are more traumatized by the lack of a supportive healthcare system than the virus itself. Given these realities, prevention is better than cure, and there are multiple precautionary measures available to minimize the chances of contracting the new coronaviral infection (Fig. 2).

In the meanwhile, let us not fall prey to fear, ignorance, and myth!

\section{In summary}

- Aerosols are dried droplets of typical diameter of $10 \mu \mathrm{m}$.

- Enveloped viruses, such as corona or influenza, are readily inactivated by the process of drying.

- A large number of aerosol particles may not contain infectious organisms due to limited space available in the particle, and a competition with a larger number of commensal microorganisms.
- The danger of airborne transmission of viruses is exaggerated. The experiments are conducted using abnormally high concentrations of viruses out of necessity.

- Aerosols are a potential danger in small and crowded rooms without cross-ventilation, but not in open areas. The possibility of virus-laden aerosol particles traveling between two buildings and infecting subjects at a distance is minimal.

- Enveloped viruses, such as corona, are inactivated at a faster rate on absorbent materials, such as tissue paper and newspapers. Newspapers cannot transmit viruses. Even if someone coughed on a newspaper, the amount of virus deposited on the newspaper and what can transmit back is too small to cause an infection.

- Viruses are inactivated at different rates on metal surfaces. The possibility of virus-transmission from the staircase railing to hands by touch is very small. Experiments use very high concentrations of viruses out of necessity.

\section{References}

1. van Doremalen N, Bushmaker T, Morris DH, Holbrook MG, Gamble A, Williamson BN, et al. Aerosol and surface stability of SARS-CoV-2 as compared with SARS-CoV-1. N Engl J Med. 2020;382(16):1564-7. https://doi.org/10.1056/NEJMc2004973.

2. Setti L, Passarini F, De Gennaro G, Barbieri P, Perrone MG, Borelli M, et al. Airborne transmission route of COVID-19: why 2 meters/ 6 feet of inter-personal distance could not be enough. Int J Environ Res Public Health. 2020. https://doi.org/10.3390/ ijerph17082932.

3. Bahl P, Doolan C, de Silva C, Chughtai AA, Bourouiba L, MacIntyre CR. Airborne or droplet precautions for health workers treating COVID-19? J Infect Dis. 2020. https://doi.org/10.1093/ infdis/jiaa189.

4. Sanyaolu A, Okorie C, Marinkovic A, Patidar R, Younis K, Desai P, Hosein Z, Padda I, Mangat J, Altaf M. Comorbidity and its impact on patients with COVID-19. SN Comp Clin Med. 2020;2(8):1069-76. https://doi.org/10.1007/s42399-020-00363-4.

5. Yang J, Zheng Y, Gou X, Pu K, Chen Z. Prevalence of comorbidities and its effects in patients infected with SARS-CoV-2. Int J Infect Dis. 2020;94(April):91-5.

6. Nicas M, Nazaroff WW, Hubbard A. Toward understanding the risk of secondary airborne infection: emission of respirable pathogens. J Occup Environ Hyg. 2005;2(3):143-54. https://doi. org/10.1080/15459620590918466.

7. Morawska L. Droplet fate in indoor environments, or can we prevent the spread of infection? Indoor Air. 2006;16(5):335-47. https://doi.org/10.1111/j.1600-0668.2006.00432.x.

8. Gralton J, Tovey E, McLaws ML, Rawlinson WD. The role of particle size in aerosolised pathogen transmission: a review. J Infect. 2011;62(1):1-13. https://doi.org/10.1016/j.jinf.2010.11. 010

9. Hersen G, Moularat S, Robine E, Gehin E, Corbet S, Vabret A, et al. Impact of health on particle size of exhaled respiratory 
aerosols: case-control study. Clean (Weinh). 2008;36(7):572-7. https://doi.org/10.1002/clen.200700189.

10. Romano-Bertrand S, Aho-Glele LS, Grandbastien B, Gehanno JF, Lepelletier D. Sustainabilit of SARS-CoV-2 in aerosols: should we worry about airborne transmission? J Hosp Infect. 2020;105(4):601-3. https://doi.org/10.1016/j.jhin.2020.06.018.

11. Tellier R, Li Y, Cowling BJ, Tang JW. Recognition of aerosol transmission of infectious agents: a commentary. BMC Infect Dis. 2019;19(1):101. https://doi.org/10.1186/s12879-019-3707-y.

12. Loudon RG, Roberts RM. Droplet expulsion from the respiratory tract. Am Rev Respir Dis. 1967;95(3):435-42. https://doi.org/10. 1164/arrd.1967.95.3.435.

13. Maukonen J, Matto J, Suihko ML, Saarela M. Intra-individual diversity and similarity of salivary and faecal microbiota. J Med Microbiol. 2008;57(Pt 12):1560-8. https://doi.org/10.1099/jmm. 0.47352-0.

14. Bachrach G, Leizerovici-Zigmond M, Zlotkin A, Naor R, Steinberg D. Bacteriophage isolation from human saliva. Lett Appl Microbiol. 2003;36(1):50-3. https://doi.org/10.1046/j.1472765x.2003.01262.x.

15. Pride DT, Salzman J, Haynes M, Rohwer F, Davis-Long C, White RA 3rd, et al. Evidence of a robust resident bacteriophage population revealed through analysis of the human salivary virome. ISME J. 2012;6(5):915-26. https://doi.org/10.1038/ismej.2011. 169.

16. Duguid JP. The size and the duration of air-carriage of respiratory droplets and droplet-nuclei. J Hyg (Lond). 1946;44(6):471-9. https://doi.org/10.1017/s0022172400019288.

17. Rubbo SD, Benjamin M. Transmission of haemolytic streptococci. J Hyg (Lond). 1953;51(2):278-92. https://doi.org/10.1017/ s0022172400015709.

18. Lloyd-Smith JO, Schreiber SJ, Kopp PE, Getz WM. Superspreading and the effect of individual variation on disease emergence. Nature. 2005;438(7066):355-9. https://doi.org/10. 1038/nature04153.

19. May KR, Druett HA, Packman LP. Toxicity of open air to a variety of microorganisms. Nature. 1969;221(5186):1146-7. https://doi.org/10.1038/2211146a0.

20. de Mik G, de Groot I. Mechanisms of inactivation of bacteriophage phiX174 and its DNA in aerosols by ozone and ozonized cyclohexene. J Hyg (Lond). 1977;78(2):199-211. https://doi.org/ 10.1017/s0022172400056096.

21. Hobday RA. The open-air factor and infection control. J Hosp Infect. 2019;103(1):e23-4. https://doi.org/10.1016/j.jhin.2019.04. 003.

22. Atkinson MP, Wein LM. Quantifying the routes of transmission for pandemic influenza. Bull Math Biol. 2008;70(3):820-67. https://doi.org/10.1007/s11538-007-9281-2.

23. Riley RL. Airborne pulmonary tuberculosis. Bacteriol Rev. 1961;25:243-8.

24. Alford RH, Kasel JA, Gerone PJ, Knight V. Human influenza resulting from aerosol inhalation. Proc Soc Exp Biol Med. 1966;122(3):800-4. https://doi.org/10.3181/00379727-122-31255.

25. van Elden LJ, Nijhuis M, Schipper P, Schuurman R, van Loon AM. Simultaneous detection of influenza viruses A and B using real-time quantitative PCR. J Clin Microbiol. 2001;39(1):196-200. https://doi.org/10.1128/JCM.39.1.196-200. 2001.

26. Ward CL, Dempsey MH, Ring CJ, Kempson RE, Zhang L, Gor $\mathrm{D}$, et al. Design and performance testing of quantitative real time PCR assays for influenza A and B viral load measurement. J Clin Virol. 2004;29(3):179-88. https://doi.org/10.1016/S13866532(03)00122-7.

27. Mercatelli D, Giorgi FM. Geographic and genomic distribution of SARS-CoV-2 mutations. Front Microbiol. 2020;11:1800. https:// doi.org/10.3389/fmicb.2020.01800.
28. Jensen S, Thomsen AR. Sensing of RNA viruses: a review of innate immune receptors involved in recognizing RNA virus invasion. J Virol. 2012;86(6):2900-10. https://doi.org/10.1128/ JVI.05738-11.

29. Lim YX, Ng YL, Tam JP, Liu DX. Human coronaviruses: a review of virus-host interactions. Diseases. 2016. https://doi.org/ 10.3390/diseases4030026.

30. Roy CJ, Milton DK. Airborne transmission of communicable infection-the elusive pathway. $N$ Engl $J$ Med. 2004;350(17):1710-2. https://doi.org/10.1056/NEJMp048051.

31. Ong SWX, Tan YK, Chia PY, Lee TH, Ng OT, Wong MSY, et al. Air, surface environmental, and personal protective equipment contamination by severe acute respiratory syndrome coronavirus 2 (SARS-CoV-2) from a symptomatic patient. JAMA. 2020. https://doi.org/10.1001/jama.2020.3227.

32. Liu Y, Ning Z, Chen Y, Guo M, Liu Y, Gali NK, et al. Aerodynamic analysis of SARS-CoV-2 in two Wuhan hospitals. Nature. 2020;582(7813):557-60. https://doi.org/10.1038/s41586020-2271-3.

33. Asano Y, Iwayama S, Miyata T, Yazaki T, Ozaki T, Tsuzuki K, et al. Spread of varicella in hospitalized children having no direct contact with an indicator zoster case and its prevention by a live vaccine. Biken J. 1980;23(3):157-61.

34. Gustafson TL, Lavely GB, Brawner ER Jr, Hutcheson RH Jr, Wright PF, Schaffner W. An outbreak of airborne nosocomial varicella. Pediatrics. 1982;70(4):550-6.

35. Weber TP, Stilianakis NI. Inactivation of influenza A viruses in the environment and modes of transmission: a critical review. J Infect. 2008;57(5):361-73. https://doi.org/10.1016/j.jinf.2008. 08.013 .

36. Lowen AC, Mubareka S, Steel J, Palese P. Influenza virus transmission is dependent on relative humidity and temperature. PLoS Pathog. 2007;3(10):1470-6. https://doi.org/10.1371/jour nal.ppat.0030151.

37. Lowen AC, Steel J, Mubareka S, Palese P. High temperature $\left(30{ }^{\circ} \mathrm{C}\right)$ blocks aerosol but not contact transmission of influenza virus. J Virol. 2008;82(11):5650-2. https://doi.org/10.1128/JVI. 00325-08.

38. Polozov IV, Bezrukov L, Gawrisch K, Zimmerberg J. Progressive ordering with decreasing temperature of the phospholipids of influenza virus. Nat Chem Biol. 2008;4(4):248-55. https://doi. org/10.1038/nchembio. 77 .

39. Thomas Y, Vogel G, Wunderli W, Suter P, Witschi M, Koch D, et al. Survival of influenza virus on banknotes. Appl Environ Microbiol. 2008;74(10):3002-7. https://doi.org/10.1128/AEM. 00076-08.

40. Bean B, Moore BM, Sterner B, Peterson LR, Gerding DN, Balfour HH Jr. Survival of influenza viruses on environmental surfaces. J Infect Dis. 1982;146(1):47-51. https://doi.org/10.1093/ infdis/146.1.47.

41. Rosenberg HF, Domachowske JB. Eosinophils, ribonucleases and host defense: solving the puzzle. Immunol Res. 1999;20(3):261-74. https://doi.org/10.1007/BF02790409.

42. Holley RW, Apgar J, Merrill SH. Evidence for the liberation of a nuclease from human fingers. J Biol Chem. 1961;236:42-3.

43. Probst J, Brechtel S, Scheel B, Hoerr I, Jung G, Rammensee HG, et al. Characterization of the ribonuclease activity on the skin surface. Genet Vaccines Ther. 2006;4:4. https://doi.org/10.1186/ 1479-0556-4-4.

44. Ng SK. Possible role of an animal vector in the SARS outbreak at Amoy Gardens. Lancet. 2003;362(9383):570-2. https://doi.org/ 10.1016/S0140-6736(03)14121-9.

Publisher's Note Springer Nature remains neutral with regard to jurisdictional claims in published maps and institutional affiliations. 